\title{
Alpha-I Adrenergic Receptors are Localized on Presynaptic Elements in the Nucleus Accumbens and Regulate Mesolimbic Dopamine Transmission
}

\author{
Darlene A Mitrano', Jason P Schroeder', Yoland Smith ${ }^{2,3}$, James J Cortright ${ }^{4}$, Nancy Bubula ${ }^{4}$, Paul Vezina $^{4}$ \\ and David Weinshenker*, \\ 'Department of Human Genetics, Emory University School of Medicine, Atlanta, GA, USA; ${ }^{2}$ Yerkes National Primate Research Center, \\ Emory University, Atlanta, GA, USA; ${ }^{3}$ Department of Neurology, Emory University, Atlanta, GA, USA; ${ }^{4}$ Department of Psychiatry and Behavioral \\ Neuroscience, The University of Chicago, Chicago, IL, USA
}

\begin{abstract}
Brainstem noradrenergic neurons innervate the mesocorticolimbic reward pathway both directly and indirectly, with norepinephrine facilitating dopamine (DA) neurotransmission via $\alpha \mid$-adrenergic receptors $(\alpha \mid A R s)$. Although $\alpha \mid A R$ signaling in the prefrontal cortex (PFC) promotes mesolimbic transmission and drug-induced behaviors, the potential contribution of $\alpha \mid$ ARs in other parts of the pathway, such as the ventral tegmental area (VTA) and nucleus accumbens (NAc), has not been investigated before. We found that local blockade of $\alpha \mid A R s$ in the medial NAc shell, but not the VTA, attenuates cocaine- and morphine-induced locomotion. To determine the neuronal substrates that could mediate these effects, we analyzed the cellular, subcellular, and subsynaptic localization of $\alpha$ IARs and characterized the chemical phenotypes of $\alpha \mid A R$-containing elements within the mesocorticolimbic system using single and double immunocytochemical methods at the electron microscopic (EM) level. We found that $\alpha \mid A R s$ are found mainly extra-synaptically in axons and axon terminals in the NAc and are enriched in glutamatergic and dopaminergic elements. $\alpha$ IARs are also abundant in glutamatergic terminals in the PFC, and in GABA-positive terminals in the VTA. In line with these observations, microdialysis experiments revealed that local blockade of $\alpha \mid A R s$ attenuated the increase in extracellular DA in the medial NAc shell following administration of cocaine. These data indicate that local $\alpha$ IARs control DA transmission in the medial NAc shell and behavioral responses to drugs of abuse.

Neuropsychopharmacology (2012) 37, 216 I-2172; doi: I0.1038/npp.2012.68; published online 16 May 2012
\end{abstract}

Keywords: norepinephrine; dopamine; alpha-I adrenergic; nucleus accumbens; ventral tegmental area; cocaine

\section{INTRODUCTION}

Norepinephrine is a catecholamine neurotransmitter involved in arousal, stress, and attention. Noradrenergic dysfunction is believed to contribute to neuropsychiatric disorders ranging from depression and schizophrenia to ADHD and addiction (Berridge and Waterhouse, 2003; Weinshenker and Schroeder, 2007). Norepinephrine (NE) signals via three classes of adrenergic receptors (ARs: $\alpha 1$ ARs, $\alpha 2$ ARs, and $\beta$ ARs), with the $\alpha 1$-adrenergic receptors ( $\alpha 1 \mathrm{ARs}$ ) regulating mesocorticolimbic dopamine (DA) transmission and multiple responses to drugs of abuse (Darracq et al, 1998; Drouin et al, 2002; Weinshenker et al, 2002; Zhang and Kosten, 2005; Weinshenker and Schroeder, 2007; Alsene et al, 2010). $\alpha 1$ ARs are found throughout the

*Correspondence: Dr D Weinshenker, Department of Human Genetics, Emory University School of Medicine, Whitehead 301, 615 Michael St., Atlanta, Georgia 30322, USA, Tel: + 404727 3106; Fax: + 404 7273949, E-mail: dweinshenker@genetics.emory.edu

Received 7 February 2012; revised 6 April 2012; accepted 9 April 2012 mesocorticolimbic system, and the importance of these receptors in the prefrontal cortex (PFC) for DA release and behavioral responses to drugs of abuse has been well characterized. For example, infusion of the $\alpha 1 \mathrm{AR}$ antagonist, prazosin, into the rodent medial PFC attenuates psychostimulant- and opiate-induced locomotion and DA release in the nucleus accumbens (NAc) shell (Darracq et al, 1998; Drouin et al, 2001; Weinshenker and Schroeder, 2007); however, the functional contribution to mesolimbic transmission and drug responses of local $\alpha 1 \mathrm{ARs}$ in the NAc shell and ventral tegmental area (VTA) has not been studied. Similarly, the ultrastructural localization of these receptors throughout the mesocorticolimbic system remains poorly characterized, which significantly hampers our understanding of the neural mechanisms by which the modulation of $\alpha 1 \mathrm{ARs}$ in this circuit could regulate communication between these structures and the behavioral and neurochemical effects associated with addictive drugs.

To better understand the potential target sites and mechanisms through which $\alpha 1$ ARs regulate DA transmission 
and mediate responses to drugs of abuse, we previously investigated the EM localization of $\alpha 1 \mathrm{ARs}$ in the rat striatum and ventral midbrain to determine their subcellular localization and found that $\alpha 1 \mathrm{AR}$ immunoreactivity was mainly expressed presynaptically in the dorsal and ventral striatum, VTA, and substantia nigra, with sparse postsynaptic labeling in dendrites and spines (Rommelfanger et al, 2009). These findings revealed that $\alpha 1 \mathrm{ARs}$ in the NAc were enriched in axons and axon terminals, but their specific neurochemical phenotype and functional relevance was not identified.

To expand on these initial findings, we undertook a detailed anatomical analysis of the ultrastructural organization of $\alpha 1 \mathrm{ARs}$ in the NAc, PFC, and VTA using EM immunocytochemical approaches. To understand the functional relevance of these $\alpha 1 \mathrm{ARs}$, we used a combination of in vivo microdialysis with a simple drug-induced behavior (locomotor activity) following local infusion of the $\alpha 1 \mathrm{AR}$ antagonist, terazosin, as a readout for mesolimbic transmission.

\section{MATERIALS AND METHODS}

\section{Animal Treatment for Behavioral Experiments}

Procedures were approved by the Animal Care and Use Committee of Emory University and the University of Chicago. Male Sprague-Dawley rats were individually housed in a temperature-controlled environment on a 12$\mathrm{hr}$ light/dark cycle with ad libitum access to food and water. Experiments were performed during the light cycle between 1000 and 1600 hours.

\section{Cannula Surgery for Intracranial Infusions}

Rats were anesthetized with a ketamine $(60-100 \mathrm{mg} / \mathrm{kg}) /$ xylazine $(0.1 \mathrm{mg} / \mathrm{kg})$ cocktail. Bilateral guide cannulae were implanted overlying the medial NAc shell or VTA by $2 \mathrm{~mm}$. The medial shell was chosen due to prominent projections from noradrenergic nuclei to the medial NAc shell (Berridge et al, 1997; Delfs et al, 1998). Coordinates for the medial NAc shell were $\mathrm{AP}=+1.3, \mathrm{ML}= \pm 2.5, \mathrm{DV}=-7.1$, angled at $10^{\circ}$. Coordinates for $\mathrm{VTA}$ were $\mathrm{AP}=-4.8, \mathrm{ML}= \pm-1.0$, $\mathrm{DV}=-7.0$ (Paxinos and Watson, 1998).

\section{Infusion Procedures}

Subjects were restrained and artificial cerebrospinal fluid (aCSF) or the selective $\alpha 1 \mathrm{AR}$ antagonist terazosin $(3 \mu \mathrm{g} /$ $0.5 \mu \mathrm{l} /$ side; Sigma-Aldrich, St Louis, MO) (Kyncl, 1986; Stone et al, 2001) were administered over a 3 min period using 5- $\mu \mathrm{l}$ Hamilton microsyringes. Doses of terazosin chosen were reported to blunt psychostimulant-induced behaviors, but not impair basal motor behavior (Stone et al, 2005; Alsene et al, 2010).

\section{Locomotor activity}

Drug-naïve subjects ( $n=5-8$ per group) were placed in locomotor activity chambers (San Diego Instruments, San Diego, CA) for $1 \mathrm{~h}$, then infused intracranially with aCSF or terazosin and injected with saline, morphine $(5 \mathrm{mg} / \mathrm{kg}$, ip), or cocaine $(15 \mathrm{mg} / \mathrm{kg}$, ip). Ambulations (consecutive beam breaks) were recorded. Preliminary experiments showed that cocaine primarily increased locomotion during the first $30 \mathrm{~min}$, whereas morphine increased locomotion during the second hour of the session (data not shown). Thus, we analyzed the effects of terazosin during the first $30 \mathrm{~min}$ following cocaine administration and the last $60 \mathrm{~min}$ following morphine administration.

\section{Animal Treatment for Immunocytochemistry}

Fourteen male, adult Sprague-Dawley rats (200-300 g) were anesthetized with a ketamine/medetomidine cocktail, transcardially perfused, and brain tissue was cut and prepared with $\mathrm{NaBH}_{4}$ and cryoprotectant for immunocytochemistry experiments as described previously (Mitrano and Smith, 2007).

\section{Primary Antibodies}

Table 1 describes all primary antibodies and peptides and their concentrations used in this study. The specificity of each of these antibodies has been characterized previously

Table I Antibodies Used for Immunocytochemistry Experiments

\begin{tabular}{|c|c|c|c|}
\hline Antigens & Immunogen & Manufacturer data & $\begin{array}{l}\text { Dilution } \\
\text { used }\end{array}$ \\
\hline $\begin{array}{l}\text { Alpha-I adrenergic } \\
\text { receptor }\end{array}$ & $\begin{array}{l}\text { Synthetic peptide corresponding to residues } \\
\text { K(339)FSREKKA KT(349) of 3rd intracellular loop of } \\
\text { human alpha IAR }\end{array}$ & $\begin{array}{l}\text { Thermo Scientific, Pierce Antibodies, Rabbit } \\
\text { Polyclonal, \#PAI-047 }\end{array}$ & I : 1000 \\
\hline vGluTI & $\begin{array}{l}\text { Clone N28/9; Produced against fusion protein amino } \\
\text { acids } 493-560 \text { of C-terminus of rat vGluTI }\end{array}$ & $\begin{array}{l}\text { UC Davis/NIH NeuroMab Facility, Mouse } \\
\text { Monoclonal \#75-066 }\end{array}$ & $1: 5000$ \\
\hline vGluT2 & Produced against amino acids $565-582$ of rat vGluT2 & $\begin{array}{l}\text { Millipore Guinea Pig Polyclonal (\#AB5907; } \\
\text { No longer available) }\end{array}$ & | : 5000 \\
\hline $\mathrm{TH}$ & $\begin{array}{l}\text { Clone LNCI; Tyrosine hydroxylase purified from } \\
\mathrm{PCI} 2 \text { cells }\end{array}$ & Millipore, Mouse Monoclonal, \#MAB3 I 8 & $1: 1000$ \\
\hline GABA & $\gamma$-aminobutyric acid conjugated to BSA & Sigma, Rabbit Polyclonal, \#A2052 & $1: 1000$ \\
\hline $\begin{array}{l}\text { Alpha-I adrenergic } \\
\text { receptor peptide }\end{array}$ & $\begin{array}{l}\text { Synthetic peptide: FSREKKAAKT (for pre-adsorption } \\
\text { experiments; } 5 \mathrm{mg} / \mathrm{ml} \text { ) }\end{array}$ & Peptide 2.0 (custom made) & $1: 25$ \\
\hline
\end{tabular}


(Dallvechia-Adams et al, 2002; Montana et al, 2004; Nakadate et al, 2006; Masilamoni et al, 2010), and preadsorption of the $\alpha 1 \mathrm{AR}$ antibody with the synthetic $\alpha 1 \mathrm{AR}$ peptide eliminated all labeling (data not shown).

\section{Single Immunoperoxidase Labeling for $\alpha 1$ ARs for Light Microscopy}

Sections were pre-incubated for $1 \mathrm{~h}$ as described previously (Mitrano and Smith, 2007), followed by primary antibody solutions overnight and then secondary biotinylated goat anti-rabbit IgGs (1:200; Vector Laboratories, Burlingame, CA). Next, sections were incubated with the avidin-biotinperoxidase $(\mathrm{ABC})$ complex $(1: 100$; Vector Laboratories), transferred to a $3,3^{\prime}$ diaminobenzidine tetrahydrochloride (DAB) solution (Sigma), mounted on slides and scanned with the Aperio ScanScope (SS5115). Micrographs were taken with ImageScope software (Version 10.2.0.0) and compiled into figures using Adobe Illustrator (version 11.0, Adobe Systems, San Jose, CA).

\section{Single Pre-embedding Immunogold Labeling for $\alpha 1$ ARs for EM}

Sections were pre-incubated for $30 \mathrm{~min}$ in PBS containing $5 \%$ dry milk at room temperature (RT) (Mitrano and Smith, 2007). Sections were transferred to primary antibody solutions for the $\alpha 1 \mathrm{AR}$ overnight at RT and treated for $2 \mathrm{~h}$ with secondary goat anti-rabbit IgGs conjugated with $1.4 \mathrm{~nm}$ gold particles (1:100; Nanoprobes, Yaphank, NY), followed by silver intensification of gold particles, osmification, dehydration and embedding procedures described previously (Mitrano and Smith, 2007). Tissue samples of the different brain regions (Figure 1) were chosen from areas corresponding to the following stereotaxic coordinates: NAc core and medial shell (AP coordinates between: +1.7 and + 1.2), PFC (prelimbic, layers IV and V; AP: +3.7 and +3.2 ), and VTA (AP: -5.6 and -5.8 ; Paxinos and Watson, 1998). They were then cut from the larger sections, mounted onto resin blocks, and cut into $60-\mathrm{nm}$ sections using an ultramicrotome (Leica Ultracut T2). The shell and core of the NAc were differentiated based on previous studies using Calbindin- $\mathrm{D}_{28 \mathrm{k}}$ (Meredith et al, 1996; Mitrano and Smith, 2007). The 60-nm sections were collected on Pioloformcoated copper grids and examined on the Zeiss EM-10C.

\section{Analysis of Single Immunogold Labeling}

Data were collected from 16 blocks (from four animals) of $\alpha 1$ AR-immunostained NAc core, shell, VTA, and PFC tissue as described above. Approximately 40 electron micrographs of randomly selected immunoreactive elements were taken at $\times 31500$ and saved with a CCD camera (DualView 300W; Gatan, Pleasanton, CA) controlled by DigitalMicrograph software (version 3.10.1, Gatan). The total amount of tissue examined was: $940.39 \mu \mathrm{m}^{2}$ in the NAc core, $869.54 \mu^{2}$ in the shell, $966.15 \mu \mathrm{m}^{2}$ in the VTA, and $979.03 \mu \mathrm{m}^{2}$ in the PFC. Labeled elements were categorized as dendrites, spines, unmyelinated axons, axon terminals, and glia as described by Peters et al (1991). Spines are usually mushroom-shaped and have a visible postsynaptic density apposed to an axon terminal, identified by the presence of vesicles. Unmyelinated a

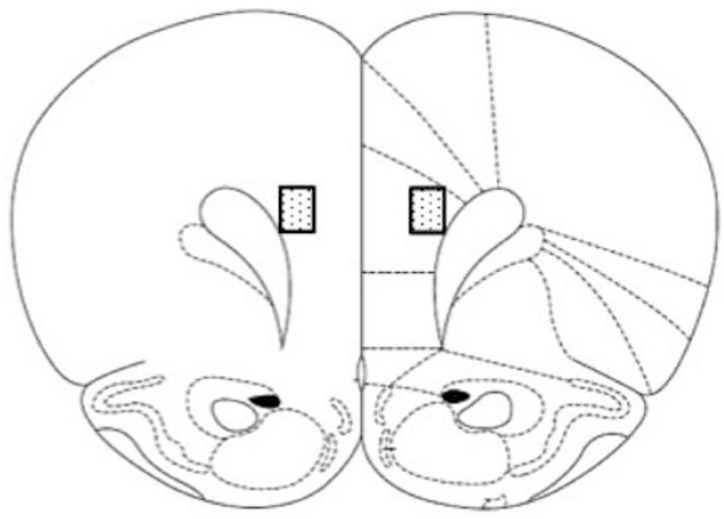

b
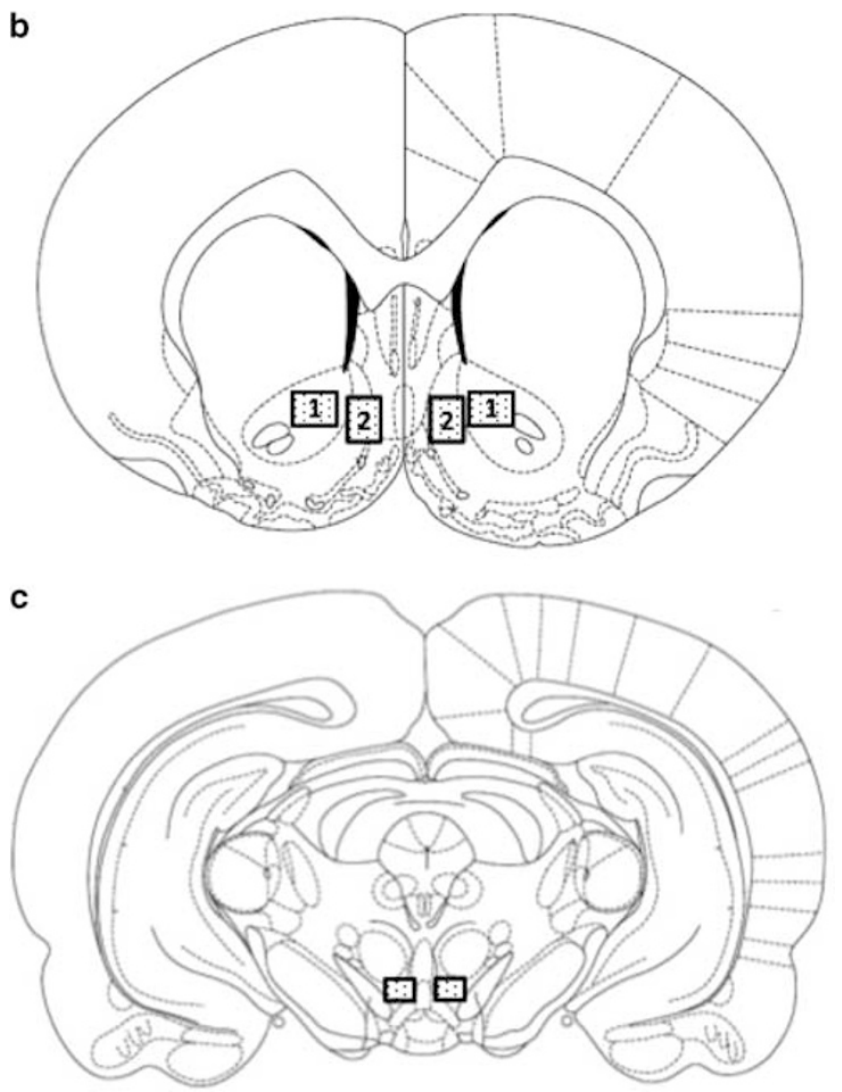

Figure I Schematic of brain regions analyzed in immunocytochemical studies. Shown are the (a) PFC (AP: + 3.2), (b) NAc (AP: + I.6; I = core, $2=$ shell), and (c) VTA (AP: -5.8). I = core, $2=$ shell). Shaded boxes indicate approximate location of tissue samples analyzed. Adapted from Paxinos and Watson (1998).

axons are small, regular, circular elements that are relatively smooth in shape, travel straight in the neuropil when seen in longitudinal plane, often contain tubules, and are frequently clustered, forming a bundle. Dendrites display different sizes and shapes, contain mitochondria, microtubules, stacks of endoplasmic reticulum and often receive synaptic contacts. Glial plexesses are usually thin, have an irregular shape, are not found in bundles, and often display a tortuous trajectory across the neuropil.

Gold particles were classified as either intracellular or plasma membrane-bound (PMB; Mitrano and Smith, 2007). PMB gold particles were further classified as perisynaptic, synaptic, or extrasynaptic (Mitrano and Smith, 2007). 
Digitally acquired micrographs were adjusted for brightness or contrast using either the DigitalMicrograph or Adobe Photoshop software (version 8.0, Adobe Systems), and then compiled into figures using Adobe Illustrator.

\section{Double Pre-embedding Immunogold for $\alpha 1 \mathrm{ARs}$ and Immunoperoxidase Labeling for Neurotransmitter Markers (TH, vGluT1, and vGluT2) for EM}

Sections were treated as described above and transferred to solutions that contained a mixture of the $\alpha 1 \mathrm{AR}$ antibody and one of the neuronal markers (TH, vGluT1, and vGluT2). Silver intensification, $\mathrm{ABC}$, and $\mathrm{DAB}$ procedures were performed as described above. Immediately following the DAB reaction, sections were subjected to osmification, dehydration, and resin embedding protocol as described previously (Mitrano and Smith, 2007).

\section{Analysis of Double Pre-embedding Labeling}

Data were collected from a total of 48 blocks. Four animals were used for each of the neuronal markers. Approximately 40 electron micrographs of randomly selected $\alpha 1 \mathrm{AR}-$ immunoreactive elements were taken at $31500 \times$. The total amount of tissue examined was: TH: NAc core: $2061.12 \mu \mathrm{m}^{2}$, shell: $2093.33 \mu \mathrm{m}^{2}$, VTA: $1977.39 \overline{\mu \mathrm{m}}^{2}$, and PFC: $798.68 \mu \mathrm{m}^{2}$; vGluT1: core: $1357.63 \mu \mathrm{m}^{2}$, shell: $1250.64 \mu \mathrm{m}^{2}$, VTA: $\overline{1043.44} \mu \mathrm{m}^{2}$, and PFC: $1345.04 \mu \mathrm{m}^{2}$; and vGluT2: core: 998.36 $\mu \mathrm{m}^{2}$, shell: $1011.24 \mu \mathrm{m}^{2}$, VTA: $1062.77 \mu \mathrm{m}^{2}$, and PFC: $1062.77 \mu \mathrm{m}^{2}$. Labeled elements were categorized as described above. The number of axon terminals containing immunogold labeling for the $\alpha 1 \mathrm{AR}$ and the percentage that also contained immunoperoxidase labeling for each of the markers (TH, vGluT1 or vGluT2) were determined.

\section{Double Pre-embedding Immunoperoxidase for the $\alpha 1 \mathrm{AR}$ and Post-embedding Immunogold Labeling for GABA for EM}

Sections were incubated in primary and secondary antibody solutions for the $\alpha 1 \mathrm{AR}$, identical to those used for light microscopy, with the exception that incubation in primary antibody lasted for $48 \mathrm{~h}$ at $4{ }^{\circ} \mathrm{C}$.

After the DAB reaction, the tissue was rinsed, treated with osmium, and dehydrated. Following dehydration, sections were treated, embedded, and baked as described previously with the exception of placing the $60-\mathrm{nm}$ sections on Pioloform-coated gold grids. Post-embedding procedures have been described previously (Dallvechia-Adams et al, 2002), taking note that secondary goat anti-rabbit IgGs were conjugated with $15 \mathrm{~nm}$ (1:50; BBInternational, Cardiff, UK). The grids were then stained with $1 \%$ uranyl acetate (in $\left.\mathrm{dH}_{2} \mathrm{O}\right)$, rinsed, and examined at the EM.

\section{Analysis of GABA Post-embedding Labeling}

Tissue was examined from four animals, from each of the four regions, totaling 16 blocks. Approximately 40-50 micrographs of $\alpha 1 \mathrm{AR}$ immunoreactive axon terminals were taken at $31500 \times$. Total amounts of tissue examined were: $1190.88 \mu \mathrm{m}^{2}$ in the core, $1165.11 \mu \mathrm{m}^{2}$ in the shell, $1387.47 \mu \mathrm{m}^{2}$ in the VTA, and $1107.85 \mu \mathrm{m}^{2}$ in the PFC.
The determination of whether or not a terminal was positive for GABA has been described previously (Dallvechia-Adams et al, 2002). The percentage of $\alpha 1 \mathrm{AR}$-immunoreactive terminals that were GABAergic was calculated with the aid of ImageJ software (NIH).

\section{In Vivo Microdialysis}

Bilateral guide cannulae were implanted in the medial NAc shell as described above. Procedures for the day before the experiment were performed as described previously (Vezina et al, 2002; Kim et al, 2005). The next day, infusion rates increased to $1.5 \mu \mathrm{l} / \mathrm{min}$, and samples were collected every $20 \mathrm{~min}$ for $1 \mathrm{~h}$ (baseline), followed by reverse dialysis of terazosin $(10$ or $100 \mu \mathrm{M})$ or vehicle for $3 \mathrm{~h}$. Cocaine $(15 \mathrm{mg} / \mathrm{kg}$, ip) was administered $1 \mathrm{~h}$ after the start of vehicle/terazosin ( $n=6-8$ per group). Terazosin doses were reported to blunt $\alpha 1 \mathrm{AR}$ agonist-induced neuronal activation and psychostimulant-induced DA overflow, but not impair basal neuronal activation or extracellular DA (Stone et al, 2006). After 5-7 days, a second microdialysis experiment was performed in the same animals with the probe inserted contralaterally. Probe placement was verified histologically.

\section{Chromatography}

DA and glutamate chromatography was performed as described previously (Kim et al, 2005). Extracellular concentrations, corrected for individual probe recoveries, were estimated from peak areas using EZChrom Elite (Agilent Technologies, Santa Clara, CA) and Shimadzu CLASS-VP (Shimadzu Scientific Instruments, Columbia, MD) software, respectively. Probe recoveries were determined in vitro and ranged from $6-11 \%$.

Data analysis. Data were analyzed by ANOVA followed by Bonferroni or Tukey's post hoc tests using Prism 4.0 for Macintosh.

\section{RESULTS}

Intra-NAc, but not intra-VTA Administration of Terazosin Attenuates Drug-induced Locomotion

Locomotor activity was recorded following infusion of aCSF or terazosin $(3 \mu \mathrm{g} / 0.5 \mu \mathrm{l} / \mathrm{side})$ into the medial NAc shell or VTA and administration of saline, cocaine $(15 \mathrm{mg} / \mathrm{kg}$, i.p.), or morphine $(5 \mathrm{mg} / \mathrm{kg}$, ip). For the NAc, two-way ANOVA showed a main effect of treatment $(F(1,24)=13.87$, $p<0.01)$ and a pre-treatment $\mathrm{x}$ treatment interaction $(\mathrm{F}(1,24)=3.56, p<0.05)$ on cocaine-induced locomotion, and a main effect of treatment $(\mathrm{F}[1,24]=12.9, p<0.01)$ and pre-treatment $(\mathrm{F}(1,24)=12.9, p<0.01)$ for morphine-induced locomotion. Tukey's post hoc analysis revealed that intra-NAc terazosin attenuated the locomotor activating effects of both drugs (Figures 2a and b). By contrast, there was only a main effect of treatment in the VTA for cocaine $(\mathrm{F}(1,19)=30.4, p<0.0001)$ and morphine $(\mathrm{F}(1,23)=31.28, p<0.0001)$; Tukey's post hoc analysis revealed that intra-VTA infusion of terazosin had no effect on cocaine- or morphine-induced locomotion (Figures 2c and d). 

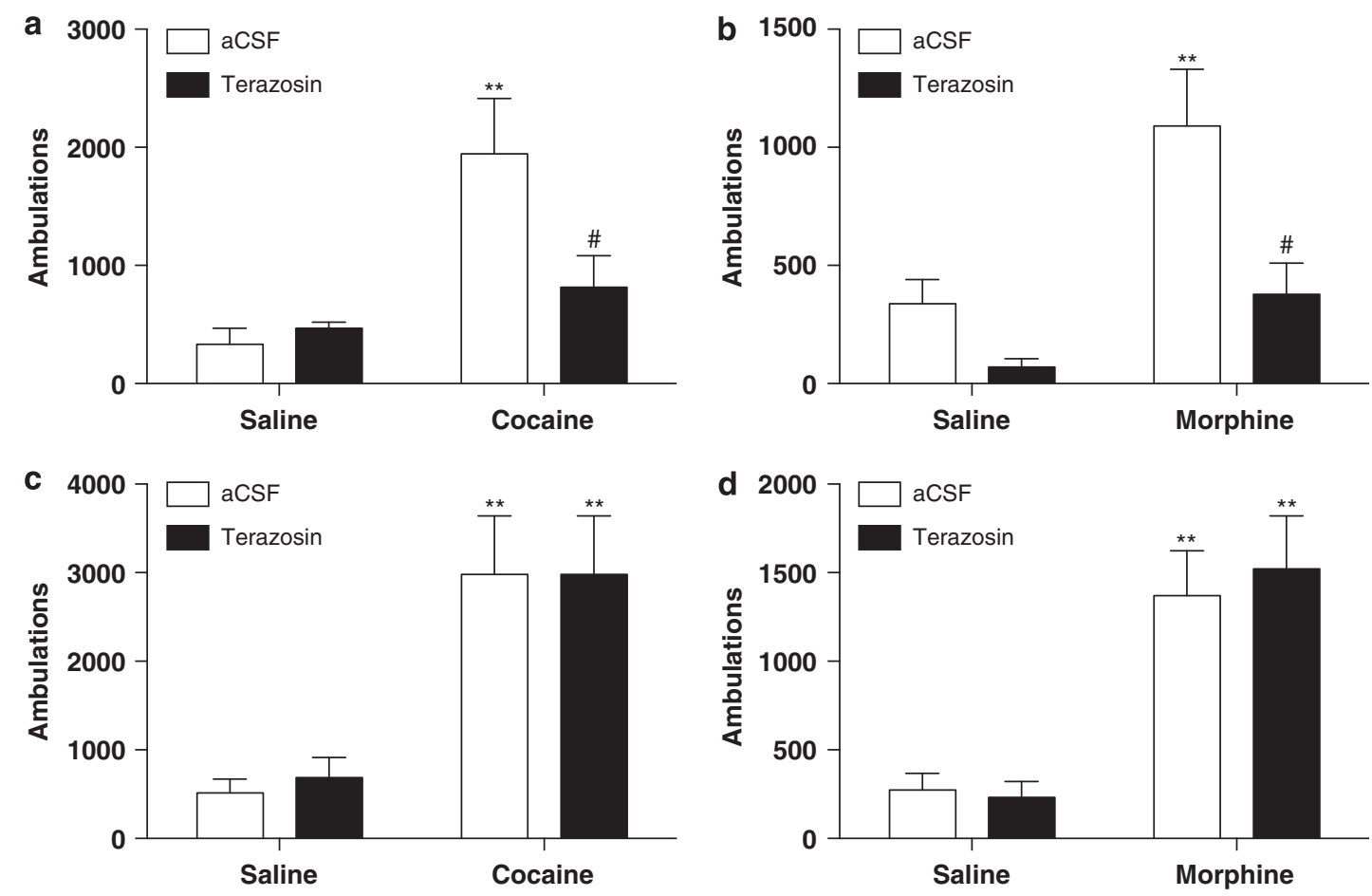

e

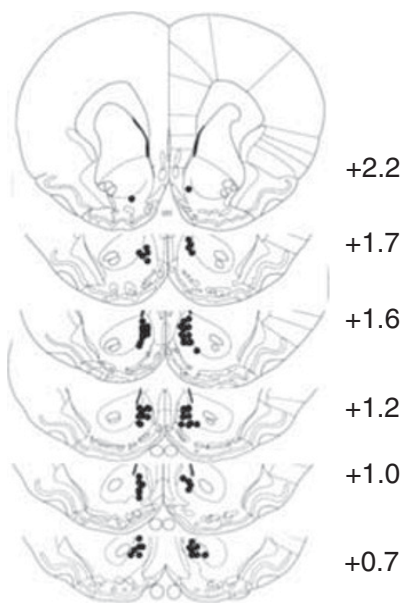

$\mathbf{f}$

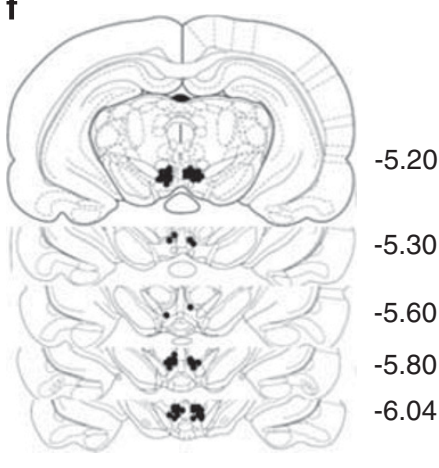

g

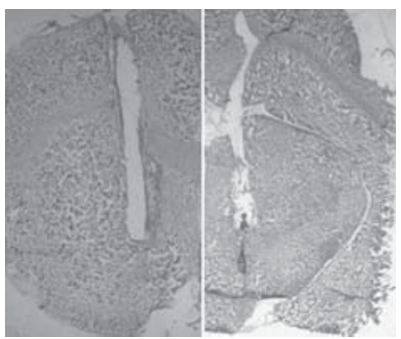

Figure 2 Blockade of $\alpha \mid$ ARs in the NAc, but not VTA, attenuates morphine- and cocaine-induced locomotion. aCSF or terazosin ( $3 \mu \mathrm{g} / 0.5 \mu \mathrm{l} / \mathrm{side})$ was infused into the NAc shell ( $a$ and b) or the VTA ( $c$ and d), followed by systemic administration of saline or cocaine ( $15 \mathrm{mg} / \mathrm{kg}$, i.p.; a and $\mathrm{c}$ ), or saline or morphine ( $5 \mathrm{mg} / \mathrm{kg}$, i.p.; $b$ and d). Shown are the total ambulations (mean \pm SEM) during the first 30 min following cocaine administration (a and c), and the total locomotor activity over the second hour following morphine administration ( $b$ and $d$ ). Also shown are schematic representations of cannula placements for the NAc (e) and VTA ( $f$ ), and sample photomicrographs of cannula tracts (g) for the NAc (left panel) and VTA (right panel). $n=5-8$ per group. $*_{*} * 0.01$ compared to aCSF-saline group; ${ }^{p}<0.05$ compared to aCSF-cocaine/aCSF-morphine group.

\section{Immunogold Labeling for $\alpha 1$ ARs Reveals Primarily Presynaptic Localization}

Using immunoperoxidase labeling of $\alpha 1 \mathrm{ARs}$ within the mesolimbic DA system, we showed previously that $\alpha 1$ ARs are localized primarily in axons and axon terminals (Rommelfanger et al, 2009). We used immunogold labeling to further assess the subcellular and subsynaptic localization of $\alpha 1 \mathrm{ARs}$ in the NAc, VTA, and PFC. Across all brain regions examined, the majority of immunogold particles were found pre-synaptically (unmyelinated axons and axon terminals; Figure 3a). Consistent with our previous findings using immunoperoxidase immunocytochemistry (Rommelfanger et al, 2009), glial expression of the $\alpha 1$ ARs was sparse, comprising only $1-5 \%$ of the total elements examined in the NAc, VTA, and PFC.

Approximately $60 \%$ of the $\alpha 1 \mathrm{ARs}$ in axons were associated with the plasma membrane, whereas $20-40 \%$ of $\alpha 1$ ARs in other elements were plasma membrane-bound (Figure $3 \mathrm{~b}$ ). A two-way ANOVA showed significant effects of element $(\mathrm{F}(3,48)=314.2 ; p<0.001)$, brain region $(\mathrm{F}(3,48)=62.79$; $p<0.001)$, and an element $\mathrm{x}$ brain region interaction $(\mathrm{F}(9,48)=14.71 ; p<0.001)$. Post hoc analysis revealed that unmyelinated axons displayed significantly higher percentages of PMB gold particles compared with dendrites, spines, and axon terminals, whereas spines and axon terminals had significantly higher percentages of PMB gold particles compared with dendrites. 

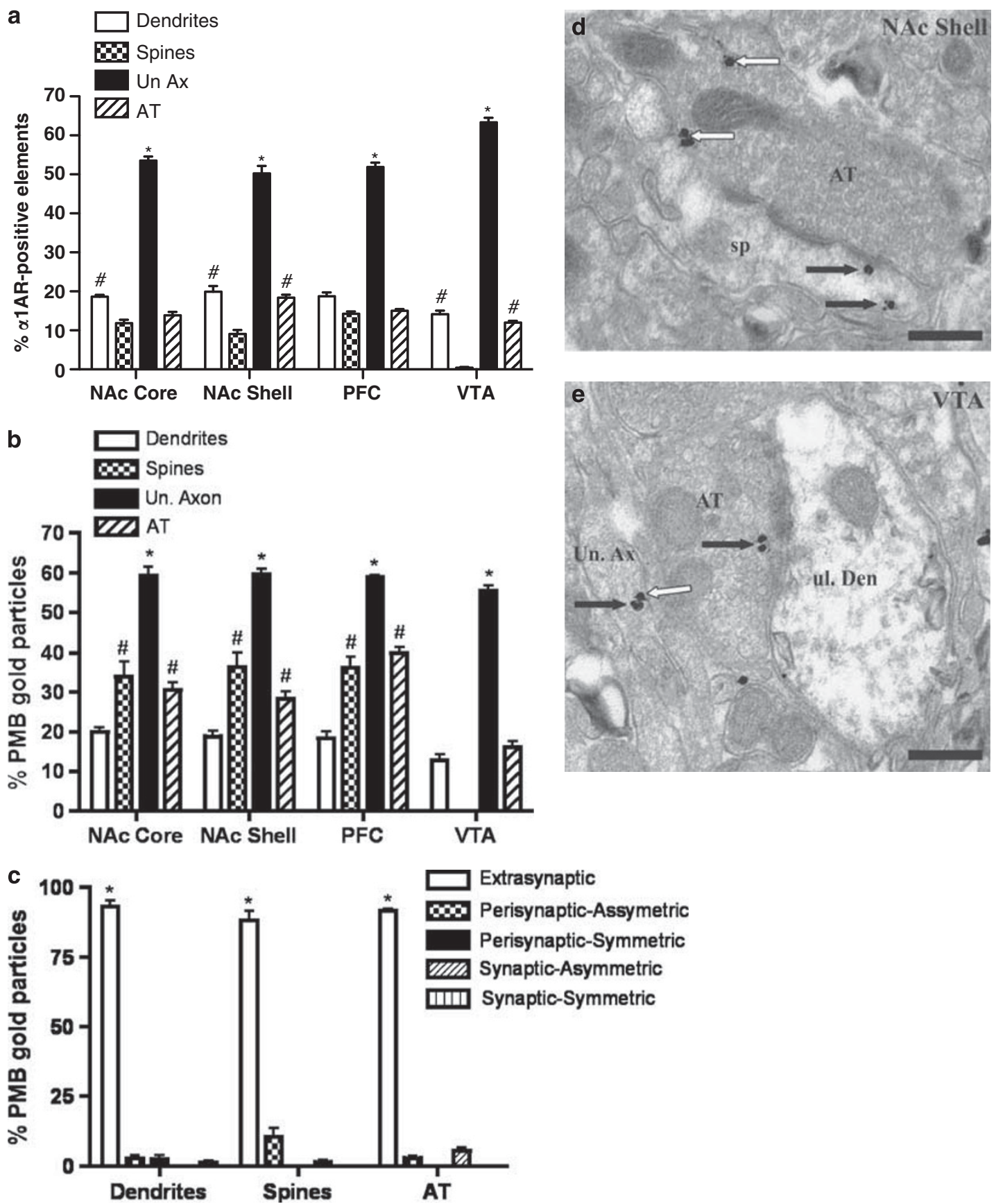

Figure 3 Ultrastructural localization of $\alpha$ IARs within the mesocorticolimbic system. (a) Percentage of gold particle immunolabeling (mean \pm SEM) for the $\alpha \mid A R$ on the various neuronal elements in the NAc core, NAc shell, PFC, and VTA. * $p<0.00$ I compared to all other elements in that brain region, ${ }^{\#} p<0.0$ I compared to spines in that brain region. (b) Relative percentage of plasma membrane-bound (PMB) immunogold labeling (mean \pm SEM) for the $\alpha \mid A R$ in various immunoreactive neuronal elements in the NAc core, NAc shell, PFC, and VTA. * $p<0.00$ I compared to all other elements in that brain region, $\#<0.01$ compared to dendrites in that brain region. (c) Subsynaptic distribution of PMB immunogold labeling (mean \pm SEM) for $\alpha \mid A R$ in various immunoreactive neuronal elements in the NAc core. The same overall pattern of labeling was found in the NAc shell, PFC, and VTA (data not shown). * $p<0.00$ I compared to all other subsynaptic categories. ( $d$ and e) illustrate representative electron micrographs of $\alpha \mid A R$ immunogold labeling in an axon terminal (AT) in the NAc shell (d) and VTA (e). A labeled spine (sp) and a labeled unmyelinated axon (Un. Ax) are also depicted in (d) and (e), respectively. White arrows indicate extrasynaptic PMB gold particles, and black arrows indicate intracellular gold particles. AT, axon terminal; PMB, plasma membranebound; sp, spine; Un. Ax, unmyelinated axon; ul. Den, unlabeled dendrite. Scale bars: $0.25 \mu \mathrm{m} . n=4$ rats.

The PMB gold particle distribution on dendrites, spines, and axon terminals was further classified by synapse type and proximity to the active zones. $\alpha 1$ ARs were almost exclusively extrasynaptic, with $<10 \%$ of these receptors found peri-synaptically or directly associated with the synaptic active zones of either asymmetric or symmetric specializations. As the data were almost identical for all brain regions examined, only one representative graph of the NAc core is presented (Figure $3 c$ ). Two-way ANOVA showed a main effect of location $(F(4,45)=2182, p<0.001)$, and a location $\mathrm{x}$ brain region interaction $(\mathrm{F}(8,45)=4.30, p<0.01)$. Post hoc analysis revealed that all neuronal elements had a 
significantly higher percentage of extrasynaptic $\alpha 1 \mathrm{AR}$ labeling compared with peri-synaptic or synaptic localization at either asymmetric or symmetric synapses.

\section{Neurotransmitter Phenotype of $\alpha 1$ AR-expressing Axon Terminals}

To determine the neurotransmitter phenotype of $\alpha 1 \mathrm{AR}$ expressing axon terminals, we used double immunoperoxidase and immunogold labeling for $\alpha 1 \mathrm{AR}$ and either vGluT1 (glutamatergic terminals originating primarily from the PFC), vGluT2 (glutamatergic terminals originating primarily from the thalamus), tyrosine hydroxylase ( $\mathrm{TH}$; catecholaminergic terminals), or GABA (GABA terminals) (Fremeau et al, 2001; Varoqui et al, 2002; Raju and Smith, 2005). Although TH labels both noradrenergic and dopaminergic elements, $\alpha 1 \mathrm{ARs}$ are not expressed by noradrenergic neurons (eg, Pieribone et al, 1994). Thus, any pre-synaptic elements that are positive for both TH and $\alpha 1 \mathrm{ARs}$ are considered dopaminergic. The results of these double labeling experiments are shown in Figure 4. There was some degree of co-localization between $\alpha 1 \mathrm{ARs}$ and all other markers in each brain region analyzed. The total extent of co-localization with all markers in each brain region was close to $100 \%$, indicating that most $\alpha 1 \mathrm{AR}$-expressing terminals are glutamatergic, dopaminergic, or GABAergic. Two-way ANOVA showed a main effect of neurotransmitter phenotype $(\mathrm{F}(3,48)=22.42, p<0.0001)$ and a neurotransmitter phenotype $\mathrm{x}$ brain region interaction $(\mathrm{F}(9,48)=12.03$, $p<0.0001$ ). Post hoc analysis revealed a significantly higher degree of $\alpha 1 \mathrm{AR}$ co-localization with vGluT1 compared with all other markers in the NAc core and PFC. By contrast, the degree of $\alpha 1 \mathrm{AR}$ co-localization with GABA was significantly higher compared with all other markers in the VTA. The degree of $\alpha 1 \mathrm{AR}$ co-localization with TH was significantly lower compared with all other markers in the PFC and compared with vGluT1 in the VTA. All markers showed similar degrees of co-localization with $\alpha 1 \mathrm{ARs}$ in the NAc shell. The chemical phenotype of $\alpha 1 \mathrm{AR}$-expressing unmyelinated axons could not be determined accurately, owing to the low level of immunoreactivity in these elements for the different neurotransmitter markers used.

\section{Intra-NAc Administration of Terazosin Attenuates Local Cocaine-induced DA Overflow}

Given the localization of $\alpha 1$ ARs to pre-synaptic dopaminergic elements in the NAc and the ability of local $\alpha 1 \mathrm{AR}$ blockade to attenuate cocaine-induced locomotor activity, we tested the effects of intra-NAc terazosin on local basal and cocaine-induced DA overflow by microdialysis. One hour following baseline dialysate collection, vehicle or terazosin $(10$ or $100 \mu \mathrm{M})$ was infused into the medial NAc shell by reverse dialysis, and cocaine $(15 \mathrm{mg} / \mathrm{kg}$, ip) was administered systemically $1 \mathrm{~h}$ later. Terazosin had no effect on baseline extracellular DA levels (Figure 5a). Although cocaine significantly elevated extracellular DA in the medial NAc shell in each treatment group, both doses of intra-NAc terazosin attenuated the effects of cocaine (Figure 5a). Twoway repeated measures ANOVA showed a significant effect of time $(\mathrm{F}(11,198)=15.44, p<0.0001)$ and a time $\mathrm{x}$ treatment interaction $(\mathrm{F}(22,198)=1.98, p<0.01)$. Post hoc analysis revealed that both the $10-\mu \mathrm{M}$ and the $100-\mu \mathrm{M}$ concentration of terazosin significantly attenuated the effects of cocaine during the first 2 time bins following cocaine administration.

\section{Neither Systemic Administration of Cocaine nor Intra-NAc Administration of Terazosin Alters Extracellular Glutamate Levels}

As $\alpha 1$ ARs were also enriched on glutamatergic terminals in the NAc, we tested the effects of intra-NAc terazosin on extracellular glutamate levels at baseline and following cocaine administration. There was a main effect of time; glutamate levels decreased over the course of the experiment $(\mathrm{F}(11,198)=6.52, p<0.0001)$. However, neither of the drug treatments significantly altered extracellular glutamate levels in the NAc (Figure 5b).

\section{DISCUSSION}

When infused into the medial NAc shell, but not the VTA, the $\alpha 1 \mathrm{AR}$ antagonist, terazosin, blunted cocaine- and morphine-induced locomotion and cocaine-induced increases in local extracellular DA. The enrichment of these receptors on pre-synaptic glutamatergic, dopaminergic, and GABAergic elements suggests that $\alpha 1$ ARs facilitate druginduced behaviors by modulating the release of other neurotransmitters within the mesocorticolimbic system.

\section{The Noradrenergic System Modulates Mesolimbic DA Transmission and Responses to Drugs of Abuse via $\alpha 1$ ARs}

The locus coeruleus (LC), A1, and A2 brainstem noradrenergic nuclei project to and facilitate mesocorticolimbic DA transmission and behavioral responses to drugs of abuse via activation of $\alpha 1$ ARs (eg, Weinshenker and Schroeder, 2007; Smith and Aston-Jones, 2008; Mejias-Aponte et al, 2009). For example, genetic or pharmacological blockade of $\alpha 1$ ARs impairs psychostimulant- and opiate-induced DA release in the NAc, locomotor activity, conditioned place preference, and re-instatement of drug seeking (eg, Darracq et al, 1998; Drouin et al, 2001; Drouin et al, 2002; Auclair et al, 2002; Weinshenker et al, 2002; Zhang and Kosten, 2005; Alsene et al, 2010). Although $\alpha 1$ ARs are found throughout the mesocorticolimbic system that underlies many responses to addictive drugs (eg, Rainbow and Biegon, 1983; Jones et al, 1985; Rommelfanger et al, 2009), only those $\alpha 1$ ARs in the PFC have been studied extensively in this context. Local depletion of NE or infusion of an $\alpha 1 \mathrm{AR}$ antagonist in the prelimbic portion of the PFC attenuates drug-induced locomotion, sensitization, and conditioned place preference (Darracq et al, 1998; Drouin et al, 2001; Ventura et al, 2003, 2005, 2007).

By contrast, very little is known about the contribution of $\alpha 1 \mathrm{ARs}$ in the NAc or VTA to mesocorticolimbic function. Infusion of an $\alpha 1 \mathrm{AR}$ antagonist into the NAc attenuates novelty-induced locomotor activity and amphetamineinduced deficits in pre-pulse inhibition (Stone et al, 2004; Alsene et al, 2010). We targeted the medial NAc shell for our behavioral and neurochemical experiments because it receives the densest noradrenergic innervation and contains the highest levels of basal and psychostimulant-evoked increases of extracellular NE in the striatum (Berridge et al, 1997; Delfs et al, 1998; McKittrick and Abercrombie, 2007). 
a
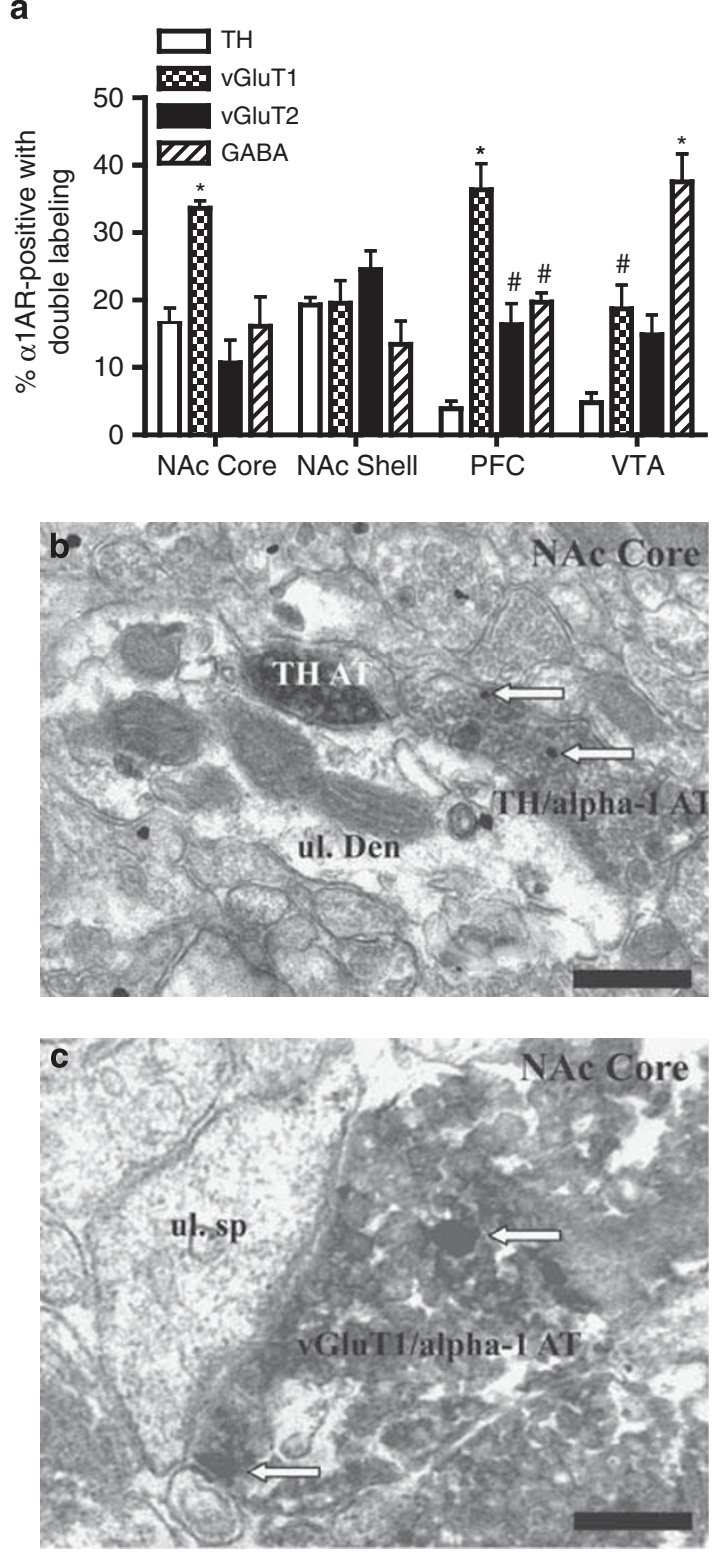
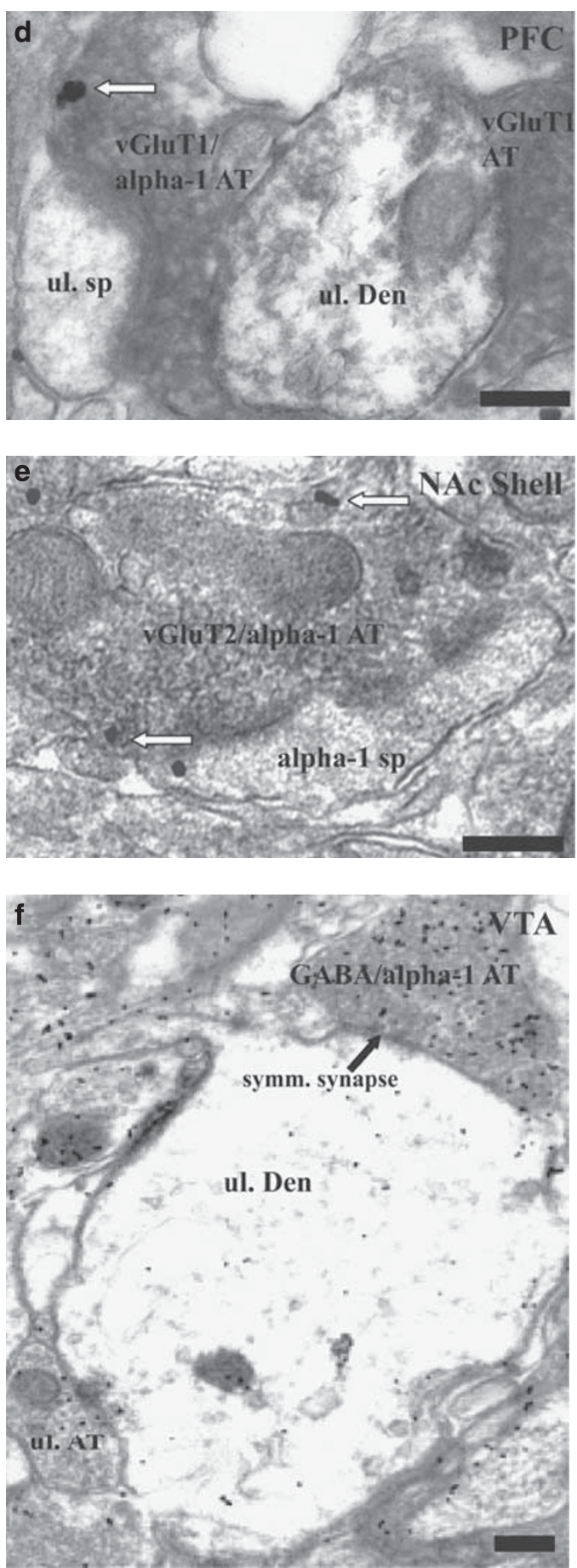

Figure 4 Neurotransmitter phenotype of $\alpha \mid A R$-immunoreactive axon terminals. (a) The percentage (mean $\pm S E M$ ) of $\alpha \mid A R$-labeled axon terminals that also contain labeling for TH, vGluTI, vGluT2, or GABA. ${ }^{*} p<0.00$ I compared to all other markers in that brain region, ${ }^{\#} p<0.05$ compared to TH in that brain region. The micrographs shown in panels (b-f) depict examples of double labeled elements. Panels B-E show immunogold labeling for the $\alpha \mid A R$ (white arrows) and immunoperoxidase labeling for TH (b), vGluTI (c and d), and vGluT2 (e) in the indicated brain regions. The micrograph in panel (f) is an example of $\alpha \mid$ AR immunoperoxidase labeling with postembedding immunogold for GABA. AT, axon terminal; sp, spine; symm. synapse, symmetric synapse; ul. Ax, unmyelinated axon; ul. AT, unlabeled axon terminal; Un. Den, unlabeled dendrite; ul. sp, unlabeled spine. Scale bars: $0.25 \mu$ m. $n=4$ rats.

The data from the present study indicate that activation of $\alpha 1 A R s$ in the medial NAc shell, but not the VTA, are required for cocaine-induced DA overflow in the medial NAc shell and the full locomotor response to cocaine and morphine. Although we cannot exclude the possibility that the terazosin is diffusing from the NAc and acting on neighboring brain structures that regulate mesolimbic DA transmission, this seems unlikely based on other studies showing behavioral effects of terazosin in the mouse NAc but not in adjacent areas (Stone et al, 2006). Although the LC innervates both cortical and subcortical structures, such as the PFC and VTA, the medial NAc shell receives 

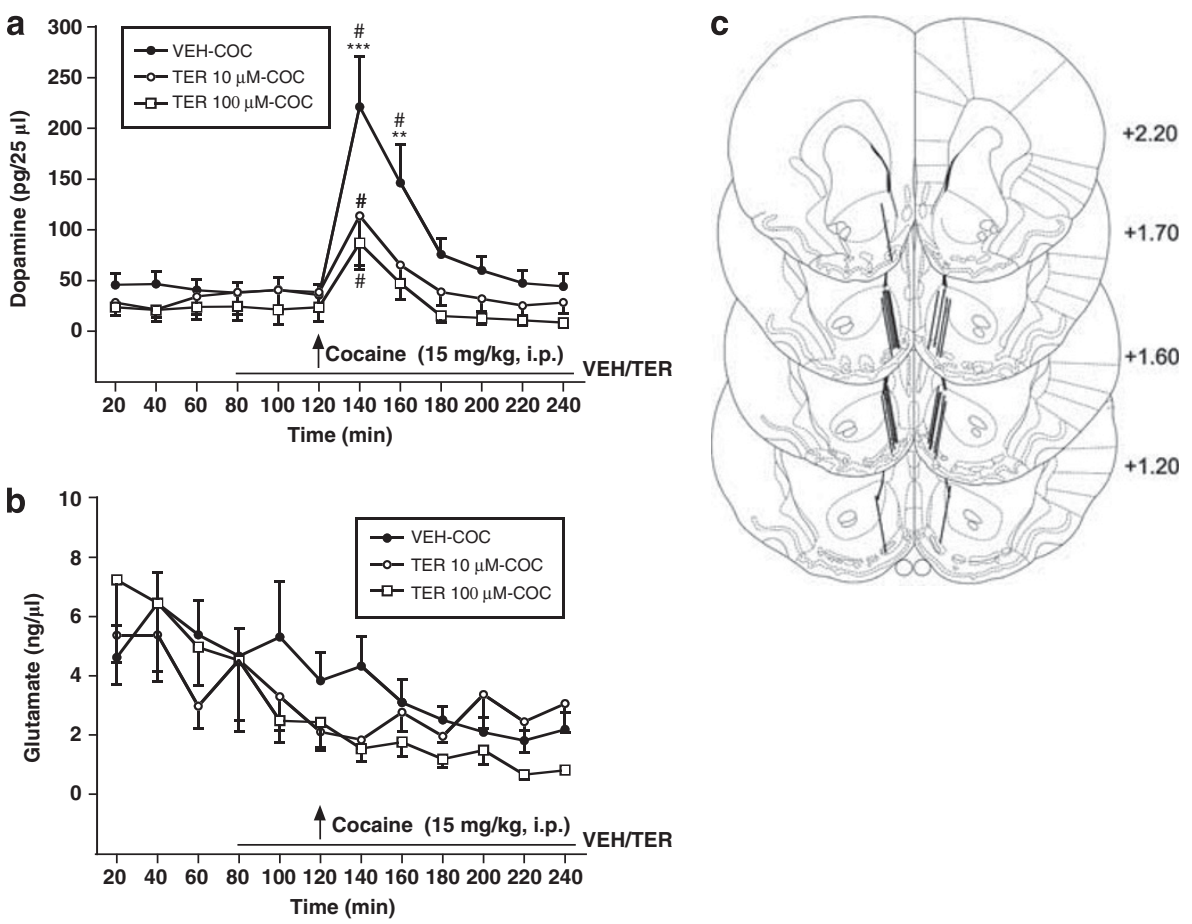

Figure 5 Blockade of $\alpha \mid A R s$ in the NAc attenuates cocaine-induced DA overflow. Following collection of baseline microdialysis samples, vehicle (VEH) or terazosin (TER; 10 or $100 \mu \mathrm{M}$ ) was infused into the NAc shell by reverse dialysis (lines at abscissae), followed by systemic administration of cocaine (I 5 mg/ $\mathrm{kg}$, i.p.) I h later (arrows), and dialysate was collected for an additional $2 \mathrm{~h}$. Shown are mean \pm SEM dopamine (a) and glutamate (b) levels, and the probe placements (c) in the NAc. ${ }^{\#} p<0.05$ compared to baseline for that treatment group, ${ }^{*} * * * 0.00$ I compared to either terazosin group, $* * * 0.05$ compared to TER I $0 \mu \mathrm{M}, p<0.0$ I compared to TER $100 \mu \mathrm{M} . n=6-8$ per group.

most of its noradrenergic input from the A2 brainstem noradrenergic cell group (Swanson and Hartman, 1975; Morrison et al, 1981; Berridge et al, 1997; Delfs et al, 1998; Liprando et al, 2004; Mejias-Aponte et al, 2009). These findings are consistent with our earlier data showing that morphine activates A2 noradrenergic neurons, in contrast to its classic inhibitory effect on LC neurons, and noradrenergic projections from A2 are critical for morphine-induced locomotion and conditioned place preference (Olson et al, 2006). The role of $\alpha 1$ ARs in the NAc core, which receives very little noradrenergic innervation (Berridge et al, 1997; Delfs et al, 1998) is unclear. The $\alpha 1$ ARs in this region could be activated by sparse local NE release or $\mathrm{NE}$ released from adjacent areas via volume transmission/ diffusion. DA, which has been shown to activate $\alpha 1$ ARs under some conditions (eg, Lin et al, 2008), could be acting as an $\alpha 1 \mathrm{AR}$ ligand in the NAc core.

\section{Neuroanatomical and Neurochemical Substrates Underlying $\alpha 1$ AR-mediated Responses to Drugs of Abuse}

It has been established previously that $\alpha 1 \mathrm{ARs}$ in the PFC are critical for DA release in the NAc neurochemical and behavioral responses to drugs of abuse; blockade of $\alpha 1$ ARs in the PFC attenuates cocaine- and morphine-induced increases in subcortical DA release and locomotor activity. The data presented here reveal that the NAc itself is another neuroanatomical target through which $\alpha 1 \mathrm{ARs}$ could mediate mesolimbic DA transmission and some of the behavioral effects elicited by psychostimulants and opiates. $\alpha 1$ ARs in the PFC. Activation of $\alpha 1$ ARs increases excitatory postsynaptic current frequency in layer $\mathrm{V}$ pyramidal cells of the PFC, and this effect is blocked by an AMPA antagonist, indicating that the effects of $\alpha 1 \mathrm{ARs}$ are mediated via glutamate (Marek and Aghajanian, 1999). We found that $\alpha 1 \mathrm{ARs}$ are enriched in vGluT1-positive axons and axon terminals, suggesting that activation of $\alpha 1 \mathrm{ARs}$ on local glutamatergic terminals in the PFC could mediate this excitation. Glutamate transmission in the PFC is dispensable for the acute locomotor effects of psychostimulants and opiates, but is critical for behavioral sensitization to these drugs. Although we observed very little co-localization between $\alpha 1 \mathrm{ARs}$ and TH in the PFC, local $\alpha 1 \mathrm{AR}$ activation does appear to enhance DA release in this brain region (Sommermeyer et al, 1995; Pan et al, 2004).

$\alpha 1 A R s$ in the NAc. Our data indicate that in the NAc, $\alpha 1$ ARs are enriched presynaptically in axon and axon terminal presynaptic elements, suggesting that $\alpha 1 \mathrm{ARs}$ act primarily by controlling the release of other neurotransmitters, rather than directly affecting the excitability of intrinsic accumbal neurons. Furthermore, $\alpha 1$ ARs are co-localized in these presynaptic elements with markers for several neurotransmitters known to have a role in drug-induced behaviors, such as DA and glutamate, being particularly enriched in vGluT1-positive axons and axon terminals originating from the PFC. DA transmission in the NAc is required for locomotor responses to psychostimulants and opiates, and we found that cocaine-induced DA overflow in the medial NAc shell was attenuated by local infusion of terazosin, which is consistent with our finding that $\alpha 1 \mathrm{ARs}$ are found in 
TH-positive terminals. Terazosin infusion had no effect on extracellular glutamate levels, although we did find a significant decrease in extracellular glutamate over time in all treatment groups, which has been observed by others (eg, Pierce et al, 1996) and could hamper interpretation of our data. However, it is well-established that acute administration of drugs of abuse to naïve subjects does not typically increase glutamate release in the NAc (eg, Pierce et al, 1996; Meyer et al, 2009). Modulation of glutamate transmission by $\alpha 1$ ARs may be critical for more complex addiction-like phenotypes, such as re-instatement of drug seeking, which does require glutamate release from PFC terminals in the NAc (see below for further discussion).

$\alpha 1 A R s$ in the VTA. Given the profound effect of $\alpha 1 \mathrm{AR}$ blockade on VTA neuron firing, the inability of intra-VTA terazosin to alter cocaine- or morphine-induced locomotor activity was somewhat surprising. Stimulation of the LC in rats increases burst firing of VTA DA neurons, whereas $\alpha 1 \mathrm{AR}$ blockade suppresses burst firing (Grenhoff and Svensson, 1989; Grenhoff et al, 1993; Grenhoff and Svensson, 1993). In slices, stimulation of $\alpha 1$ ARs depolarizes VTA cells on its own and increases amphetamine-induced DA neuron activity, even when synaptic transmission is blocked (Grenhoff et al, 1995; Paladini et al, 2001); however, $\alpha 1 \mathrm{AR}$ activation also appears to have direct and indirect inhibitory effects on VTA neurons (Paladini and Williams, 2004). $\alpha 1 \mathrm{AR}$ activation in VTA slices increases the frequencies of inhibitory postsynaptic potentials (IPSPs) in a tetrodotoxin-sensitive manner, suggesting the involvement of interneuron excitation and GABA release onto DA neurons (Grenhoff et al, 1995). This inhibitory effect of $\alpha 1 \mathrm{AR}$ activation on VTA firing is consistent with the high prevalence of $\alpha 1 \mathrm{AR}$ co-localization in GABA terminals described in the present study. Thus, $\alpha 1 \mathrm{AR}$ modulation of synaptic transmission in the VTA is clearly complex.

ג1AR Subsynaptic Localization Throughout the Mesocorticolimbic System. $\alpha 1$ ARs were mainly associated with the extrasynaptic plasma membrane in axons and localized intracellularly in dendrites, spines, and axon terminals. The extrasynaptic pattern of labeling on axons is consistent with what has been reported for other G-protein coupled catecholamine receptors such as DA receptors (Yung et al, 1995), and probably reflects the fact that catecholamines signal via 'volume transmission' rather than via classical synaptic transmission (reviewed by Fuxe et al, 2010). The high degree of intracellular labeling for the $\alpha 1 \mathrm{AR}$ is also common for G-protein coupled receptors, and may represent receptors traveling to the membrane after synthesis or trafficking to and from the membrane during de-sensitization-re-sensitization (Gainetdinov et al, 2004). There is also mounting evidence that internalized receptors have unique signaling capabilities (Calebiro et al, 2010).

\section{Conclusion}

In this study, we present evidence that local $\alpha 1 \mathrm{ARs}$ on dopaminergic terminals in the medial NAc shell regulate functional mesolimbic neurotransmission, including druginduced changes in extracellular DA levels and locomotor activity. Because we used a simple, acute behavioral paradigm that is not associated with changes in glutamate, the contribution of $\alpha 1 \mathrm{ARs}$ to glutamate transmission remains unknown. Future research will focus on the role of $\alpha$ ARs within the mesocorticolimbic circuit that may contribute to some of the more complex behaviors associated with chronic drug administration and withdrawal that require DA and/or glutamate. For example, blockade of $\alpha 1 \mathrm{ARs}$ attenuates psychostimulant- and opiateinduced sensitization (Drouin et al, 2001, 2002; Weinshenker et al, 2002; Auclair et al, 2004; Jiménez-Rivera et al, 2006), drug-primed reinstatement of cocaine, and nicotine seeking (Zhang and Kosten, 2005; Forget et al, 2010), the ability of cocaine pre-exposure to enhance subsequent cocaine self-administration (Zhang and Kosten, 2007), and the escalation of drug intake in the extended-access model of cocaine and heroin self-administration (Wee et al, 2008; Greenwell et al, 2009). Although the neuroanatomical and neurochemical substrates underlying these effects of $\alpha 1 \mathrm{AR}$ antagonism have not been identified, our data point to a contribution of alterations in drug-induced $\mathrm{DA}$ and/or glutamate release in the PFC and NAc, and potentially the VTA.

\section{ACKNOWLEDGEMENTS}

This work was supported by the following NIH Grants: NIH/ NIGMS IRACDA 5K12GM000680 (DAM), NIH/NIDA DA017963 (DW), NIH/NIDA DA027535 (DW), and NIH/ NIDA DA09397 (PV). Special thanks to Jean-Francois Pare for his technical assistance and to Cheryl Strauss for helpful editing of the manuscript.

\section{DISCLOSURE}

The authors declare no conflict of interest.

\section{REFERENCES}

Alsene KM, Fallace K, Bakshi VP (2010). Ventral striatal noradrenergic mechanisms contribute to sensorimotor gating deficits induced by amphetamine. Neuropsychopharmacology 35: 2346-2356.

Auclair A, Cotecchia S, Glowinski J, Tassin JP (2002). Damphetamine fails to increase extracellular dopamine levels in mice lacking alpha $1 \mathrm{~b}$-adrenergic receptors: relationship between functional and nonfunctional dopamine release. J Neurosci 22: 9150-9154.

Auclair A, Drouin C, Cotecchia S, Glowinski J, Tassin JP (2004). 5-HT2A and alphalb-adrenergic receptors entirely mediate dopamine release, locomotor response and behavioural sensitization to opiates and psychostimulants. Eur J Neurosci 20: 3073-3084.

Berridge CW, Stratford TL, Foote SL, Kelley AE (1997). Distribution of dopamine beta-hydroxylase-like immunoreactive fibers within the shell subregion of the nucleus accumbens. Synapse 27: 230-241.

Berridge CW, Waterhouse BD (2003). The locus coeruleusnoradrenergic system: modulation of behavioral state and state-dependent cognitive processes. Brain Res Brain Res Rev 42: 33-84. 
Calebiro D, Nikolaev VO, Persani L, Lohse MJ (2010). Signaling by internalized G-protein-coupled receptors. Trends Pharmacol Sci 31: 221-228.

Dallvechia-Adams S, Kuhar MJ, Smith Y (2002). Cocaine- and amphetamine-regulated transcript peptide projections in the ventral midbrain: colocalization with gamma-aminobutyric acid, melanin-concentrating hormone, dynorphin, and synaptic interactions with dopamine neurons. J Comp Neurol 448: 360-372.

Darracq L, Blanc G, Glowinski J, Tassin JP (1998). Importance of the noradrenaline-dopamine coupling in the locomotor activating effects of D-amphetamine. J Neurosci 18: 2729-2739.

Delfs JM, Zhu Y, Druhan JP, Aston-Jones GS (1998). Origin of noradrenergic afferents to the shell subregion of the nucleus accumbens: anterograde and retrograde tract-tracing studies in the rat. Brain Res 806: 127-140.

Drouin C, Blanc G, Trovero F, Glowinski J, Tassin JP (2001). Cortical alpha 1-adrenergic regulation of acute and sensitized morphine locomotor effects. Neuroreport 12: 3483-3486.

Drouin C, Darracq L, Trovero F, Blanc G, Glowinski J, Cotecchia S et al (2002). Alpha1b-adrenergic receptors control locomotor and rewarding effects of psychostimulants and opiates. $J$ Neurosci 22: 2873-2884.

Forget B, Wertheim C, Mascia P, Pushparaj A, Goldberg SR, Le Foll B (2010). Noradrenergic alphal receptors as a novel target for the treatment of nicotine addiction. Neuropsychopharmacology 35: $1751-1760$.

Fremeau Jr RT, Troyer MD, Pahner I, Nygaard GO, Tran $\mathrm{CH}$, Reimer RJ et al (2001). The expression of vesicular glutamate transporters defines two classes of excitatory synapse. Neuron 31: 247-260.

Fuxe K, Dahlström AB, Jonsson G, Marcellino D, Guescini M, Dam $M$ et al (2010). The discovery of central monoamine neurons gave volume transmission to the wired brain. Prog Neurobiol 90: $82-100$.

Gainetdinov RR, Premont RT, Bohn LM, Lefkowitz RJ, Caron MG (2004). Desensitization of $G$ protein-coupled receptors and neuronal functions. Annu Rev Neurosci 27: 107-144.

Greenwell TN, Walker BM, Cottone P, Zorrilla EP, Koob GF (2009). The alphal adrenergic receptor antagonist prazosin reduces heroin self-administration in rats with extended access to heroin administration. Pharmacol Biochem Behav 91: 295-302.

Grenhoff J, Nisell M, Ferre S, Aston-Jones G, Svensson TH (1993). Noradrenergic modulation of midbrain dopamine cell firing elicited by stimulation of the locus coeruleus in the rat. J Neural Transm Gen Sect 93: 11-25.

Grenhoff J, North RA, Johnson SW (1995). Alpha 1-adrenergic effects on dopamine neurons recorded intracellularly in the rat midbrain slice. Eur J Neurosci 7: 1707-1713.

Grenhoff J, Svensson TH (1989). Clonidine modulates dopamine cell firing in rat ventral tegmental area. Eur J Pharmacol 165: $11-18$.

Grenhoff J, Svensson TH (1993). Prazosin modulates the firing pattern of dopamine neurons in rat ventral tegmental area. Eur $J$ Pharmacol 233: 79-84.

Jiménez-Rivera CA, Feliu-Mojer M, Vázquez-Torres R (2006). Alpha-noradrenergic receptors modulate the development and expression of cocaine sensitization. Ann N Y Acad Sci 1074: 390402.

Jones LS, Gauger LL, Davis JN (1985). Anatomy of brain alpha 1adrenergic receptors: in vitro autoradiography with [125I]-heat. J Comp Neurol 231: 190-208.

Kim JH, Austin JD, Tanabe L, Creekmore E, Vezina P (2005). Activation of group II mGlu receptors blocks the enhanced drug taking induced by previous exposure to amphetamine. Eur $J$ Neurosci 21: 295-300.

Kyncl JJ (1986). Pharmacology of terazosin. Am J Med 80: 12-19. Lin Y, Quartermain D, Dunn AJ, Weinshenker D, Stone EA (2008). Possible dopaminergic stimulation of locus coeruleus alpha1- adrenoceptors involved in behavioral activation. Synapse 62: 516-523.

Liprando LA, Miner LH, Blakely RD, Lewis DA, Sesack SR (2004). Ultrastructural interactions between terminals expressing the norepinephrine transporter and dopamine neurons in the rat and monkey ventral tegmental area. Synapse 52: 233-244.

Marek GJ, Aghajanian GK (1999). 5-HT2A receptor or alpha1adrenoceptor activation induces excitatory postsynaptic currents in layer V pyramidal cells of the medial prefrontal cortex. Eur J Pharmacol 367: 197-206.

Masilamoni G, Votaw J, Howell L, Villalba RM, Goodman M, Voll RJ et al (2010). (18)F-FECNT: validation as PET dopamine transporter ligand in parkinsonism. Exp Neurol 226: 265-273.

McKittrick CR, Abercrombie ED (2007). Catecholamine mapping within nucleus accumbens: differences in basal and amphetamine-stimulated efflux of norepinephrine and dopamine in shell and core. J Neurochem 100: 1247-1256.

Mejias-Aponte CA, Drouin C, Aston-Jones G (2009). Adrenergic and noradrenergic innervation of the midbrain ventral tegmental area and retrorubral field: prominent inputs from medullary homeostatic centers. J Neurosci 29: 3613-3626.

Meredith GE, Pattiselanno A, Groenewegen HJ, Haber SN (1996). Shell and core in monkey and human nucleus accumbens identified with antibodies to calbindin-D28k. J Comp Neurol 365: 628-639.

Meyer PJ, Meshul CK, Phillips TJ (2009). Ethanol- and cocaineinduced locomotion are genetically related to increases in accumbal dopamine. Genes Brain Behav 8: 346-355.

Mitrano DA, Smith Y (2007). Comparative analysis of the subcellular and subsynaptic localization of mGluR1a and mGluR5 metabotropic glutamate receptors in the shell and core of the nucleus accumbens in rat and monkey. J Comp Neurol 500: 788-806.

Montana V, Ni Y, Sunjara V, Hua X, Parpura V (2004). Vesicular glutamate transporter-dependent glutamate release from astrocytes. J Neurosci 24: 2633-2642.

Morrison JH, Molliver ME, Grzanna R, Coyle JT (1981). The intracortical trajectory of the coeruleo-cortical projection in the rat: a tangentially organized cortical afferent. Neuroscience 6: 139-158.

Nakadate K, Imamura K, Watanabe Y (2006). Cellular and subcellular localization of alpha-1 adrenoceptors in the rat visual cortex. Neuroscience 141: 1783-1792.

Olson VG, Heusner CL, Bland RJ, During MJ, Weinshenker D, Palmiter RD (2006). Role of noradrenergic signaling by the nucleus tractus solitarius in mediating opiate reward. Science 311: 1017-1020.

Paladini CA, Fiorillo CD, Morikawa H, Williams JT (2001). Amphetamine selectively blocks inhibitory glutamate transmission in dopamine neurons. Nat Neurosci 4: 275-281.

Paladini CA, Williams JT (2004). Noradrenergic inhibition of midbrain dopamine neurons. J Neurosci 24: 4568-4575.

Pan WH, Yang SY, Lin SK (2004). Neurochemical interaction between dopaminergic and noradrenergic neurons in the medial prefrontal cortex. Synapse 53: 44-52.

Paxinos G, Watson C (1998). The Rat Brain In Stereotaxic Coordinates. Academic Press Limited: London.

Peters A, Palay S, Webster HD (1991). The fine structure of the nervous system: Neurons and their supporting cells.. Oxford University Press: New York.

Pierce RC, Bell K, Duffy P, Kalivas PW (1996). Repeated cocaine augments excitatory amino acid transmission in the nucleus accumbens only in rats having developed behavioral sensitization. J Neurosci 16: 1550-1560.

Pieribone VA, Nicholas AP, Dagerlind A, Hökfelt T (1994). Distribution of alpha 1 adrenoceptors in rat brain revealed by in situ hybridization experiments utilizing subtype-specific probes. J Neurosci 14: 4252-4268. 
Rainbow TC, Biegon A (1983). Quantitative autoradiography of $[3 \mathrm{H}]$ prazosin binding sites in rat forebrain. Neurosci Lett 40: 221-226.

Raju DV, Smith Y (2005). Differential localization of vesicular glutamate transporters 1 and 2 in the rat striatum. In: Bolam JP, Ingham CA, Magill PJ, (eds). The basal ganglia VIII. Springer Science: New York, pp 601-610.

Rommelfanger KS, Mitrano DA, Smith Y, Weinshenker D (2009). Light and electron microscopic localization of alpha-1 adrenergic receptor immunoreactivity in the rat striatum and ventral midbrain. Neuroscience 158: 1530-1540.

Smith RJ, Aston-Jones G (2008). Noradrenergic transmission in the extended amygdala: role in increased drug-seeking and relapse during protracted drug abstinence. Brain Struct Funct 213: 43-61.

Sommermeyer H, Frielingsdorf J, Knorr A (1995). Effects of prazosin on the dopaminergic neurotransmission in rat brain. Eur J Pharmacol 276: 267-270.

Stone EA, Lin Y, Ahsan R, Quartermain D (2004). Gross mapping of alpha1-adrenoceptors that regulate behavioral activation in the mouse brain. Behav Brain Res 152: 167-175.

Stone EA, Lin Y, Ahsan MR, Quartermain D (2005). Evidence of roles of central alpha1-adrenoceptors and epinephrine in orexin A-induced hyperactivity in mice. Neurosci Lett 381: 325-328.

Stone EA, Rosengarten H, Lin Y, Quartermain D (2001). Pharmacological blockade of brain alpha1-adrenoceptors as measured by ex vivo [3H]prazosin binding is correlated with behavioral immobility. Eur J Pharmacol 420: 97-102.

Stone EA, Yan L, Ahsan MR, Lehmann ML, Yeretsian J, Quartermain D (2006). Role of CNS alpha1-adrenoceptor activity in central fos responses to novelty. Synapse 59: 299-307.

Swanson LW, Hartman BK (1975). The central adrenergic system. An immunofluorescence study of the location of cell bodies and their efferent connections in the rat utilizing dopamine-betahydroxylase as a marker. J Comp Neurol 163: 467-505.

Varoqui H, Schafer MK, Zhu H, Weihe E, Erickson JD (2002). Identification of the differentiation-associated $\mathrm{Na}+/ \mathrm{PI}$ transporter as a novel vesicular glutamate transporter expressed in a distinct set of glutamatergic synapses. J Neurosci 22: 142-155.
Ventura R, Alcaro A, Puglisi-Allegra S (2005). Prefrontal cortical norepinephrine release is critical for morphine-induced reward, reinstatement and dopamine release in the nucleus accumbens. Cereb Cortex 15: 1877-1886.

Ventura R, Cabib S, Alcaro A, Orsini C, Puglisi-Allegra S (2003). Norepinephrine in the prefrontal cortex is critical for amphetamine-induced reward and mesoaccumbens dopamine release. J Neurosci 23: 1879-1885.

Ventura R, Morrone C, Puglisi-Allegra S (2007). Prefrontal/ accumbal catecholamine system determines motivational salience attribution to both reward- and aversion-related stimuli. Proc Natl Acad Sci USA 104: 5181-5186.

Vezina P, Lorrain DS, Arnold GM, Austin JD, Suto N (2002). Sensitization of midbrain dopamine neuron reactivity promotes the pursuit of amphetamine. J Neurosci 22: 4654-4662.

Wee S, Mandyam CD, Lekic DM, Koob GF (2008). Alpha 1noradrenergic system role in increased motivation for cocaine intake in rats with prolonged access. Eur Neuropsychopharmacol 18: 303-311.

Weinshenker D, Miller NS, Blizinsky K, Laughlin ML, Palmiter RD (2002). Mice with chronic norepinephrine deficiency resemble amphetamine-sensitized animals. Proc Natl Acad Sci USA 99: 13873-13877.

Weinshenker D, Schroeder JP (2007). There and back again: a tale of norepinephrine and drug addiction. Neuropsychopharmacology 32: 1433-1451.

Yung KKL, Bolam JP, Smith AD, Hersch SM, Ciliax BJ, Levey AI (1995). Immunocytochemical localization of D1 and D2 receptors in the basal ganglia of the rat: Light and electron microscopy. Neuroscience 65: 709-730.

Zhang XY, Kosten TA (2005). Prazosin, an alpha-1 adrenergic antagonist, reduces cocaine-induced reinstatement of drugseeking. Biol Psychiatry 57: 1202-1204.

Zhang XY, Kosten TA (2007). Previous exposure to cocaine enhances cocaine self-administration in an alpha 1-adrenergic receptor dependent manner. Neuropsychopharmacology 32: 638-645. 